\title{
SURFACE ROUGHNESS CONSIDERATIONS IN DESIGN FOR ADDITIVE MANUFACTURING - A LITERATURE REVIEW
}

\author{
Obilanade, Didunoluwa (1); \\ Dordlofva, Christo (1,2); \\ Törlind, Peter (1) \\ 1: Luleå University of Technology; \\ 2: GKN Aerospace Engine Systems
}

\begin{abstract}
One often-cited benefit of using metal additive manufacturing (AM) is the possibility to design and produce complex geometries that suit the required function and performance of end-use parts. In this context, laser powder bed fusion (LPBF) is one suitable AM process. Due to accessibility issues and cost-reduction potentials, such 'complex' LPBF parts should utilise net-shape manufacturing with minimal use of post-process machining. The inherent surface roughness of LPBF could, however, impede part performance, especially from a structural perspective and in particular regarding fatigue. Engineers must therefore understand the influence of surface roughness on part performance and how to consider it during design. This paper presents a systematic literature review of research related to LPBF surface roughness. In general, research focuses on the relationship between surface roughness and LPBF build parameters, material properties, or post-processing. Research on design support on how to consider surface roughness during design for AM is however scarce. Future research on such supports is therefore important given the effects of surface roughness highlighted in other research fields.
\end{abstract}

Keywords: Laser Powder Bed Fusion, Surface Roughness, Design for Additive Manufacturing (DfAM), Design for X (DfX), Design engineering

\section{Contact:}

Obilanade, Didunoluwa Abiodun

Luleå University of Technology

Product Innovation

Sweden

didunoluwa.obilanade@1tu.se 


\section{INTRODUCTION}

Metal additive manufacturing (AM), and in particular laser powder bed fusion (LPBF), has potential for the design and production of parts with novel and innovative design solutions. As an example, one attractive possibility with using LPBF is to design parts to save weight (Ewald and Schlattmann, 2018). When a part is designed to utilise the capabilities of LPBF for the purpose of weight-saving, the result is often an intricate geometry that may be costly and difficult to post-process. Parts manufactured with LPBF are characterised by rather rough 'as-built' surfaces, hence intricate geometries are bound to include surfaces with a degree of roughness. The surface quality of LPBF parts is affected by variables such as build orientation, overhangs, support structure, but also process-related parameters such as layer thickness, melt theme, material and powder size. For some applications, rough and textured surfaces might be favourable. Saltzman et al. (2018) replicated a conventional stamped aluminium aircraft heat exchanger (HX) for engine oil cooling, with minor modifications to assure buildability with LPBF. The as-built roughness of the LPBF HX was measured to be significantly higher than the conventional design $(\mathrm{Sa}=24.0 \mu \mathrm{m}$ vs. $0.316 \mu \mathrm{m})$. Results from testing showed up to $10 \%$ increase in heat transfer (but also a duplication in pressure loss) which was believed to be an effect of the surface roughness (rather than geometry changes). However, for many applications, the surface roughness of LPBF parts is generally too high in the as-built state to be used in actual end-products because rough surfaces can have an adverse effect on performance, especially with regard to fatigue. For the design of a rocket engine turbine, Dordlofva et al. (2019) applied additional safety factors to account for uncertainties in the LPBF material and its surface roughness. Subsequent fatigue testing on machined and as-built specimens showed a significant impact of surface roughness on fatigue properties where e.g., the high cycle fatigue limit was decreased by up to $40 \%$ due to the surface. Hence, it is essential for engineers to understand and consider how surface quality is affected by part geometry, its production, and how surface quality impacts part performance. In general, guidelines for AM of metals (e.g., Diegel et al., 2019; Schnabel et al., 2017), standards (e.g., ISO/ASTM 52910, 2018; ISO/ASTM 52911-1-19, 2019) and machine specific guidelines include recommendations of maximum overhang angles (without support structures). Exceeding these recommendations leads to rough surfaces, porosities, dross formation (attachment of powder to down-skin surfaces) and even build failures (Piscopo et al., 2019). As an example, Diegel et al. (2019) list maximum recommended feature overhangs for specific machines and materials. The VDI 3405 Part 3 (2015) shows a fundamental relationship between skin-angle, down-skin angle and surface roughness. The best results are achieved on horizontal surfaces and surface roughness increase when the down-skin angle decreases (shallow angle is worse). Test prints from VTT (Kokkonen et al., 2016) show that the main contributing factor for surface roughness is the down-skin angle and that no significant dependency was detected on the angular placement of surfaces. These guidelines and examples are general and provide 'rules of thumb' for engineers. However, for specific applications, they can be challenged, and parametric feasibility studies can be needed for specific material-machine-geometry combinations (Dordlofva and Törlind, 2020).

This paper presents an initial literature review on research focusing on different aspects of surface roughness and its impact on parts manufactured with metal LPBF. The purpose of the paper is to give a general description of current knowledge on surface roughness, and to identify future research on support for how surface roughness should be considered during design for AM.

\section{METHOD}

The literature review was conducted in 6 stages based on the PRISMA approach (Moher et al., 2009) as illustrated in Figure 1. The review undertook four PRISMA recommended review phases; article identification, screening articles for duplicates, conducting eligibility checks and conducting a qualitative synthesis of the eligible articles. No time limit on article publication dates were set for inclusion in the review. All 499 articles found were published between 2010 to 2021.

STAGE 1: SCOPUS and The Design Society library were chosen as the databases for the search. Two search terms were used, one for a focused narrow search and a second for a more general search of the subject area. The search term used for a narrow search $(\mathrm{Nr})$ was ("design for additive manufacturing" surface AND roughness) whereas for the broad search $(\mathrm{Br})$ the term ("additive manufacturing" roughness AND powder) was used. The narrow search enabled a general check of articles specifically referencing design for $A M$ in relation to surface roughness. 


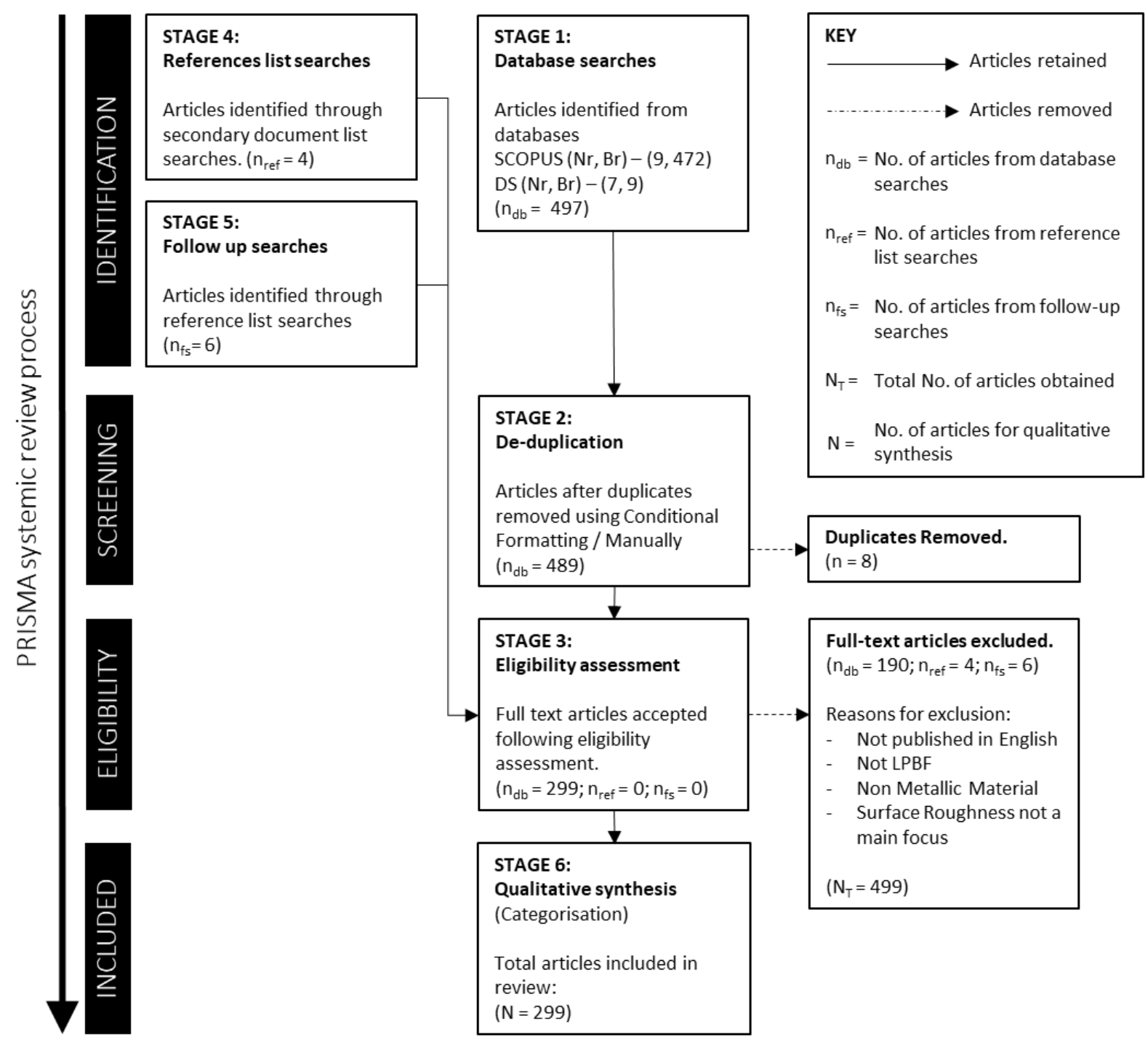

Figure 1. Flow diagram of the systematic review process (based on a generic diagram by Moher et al., 2009).

The broad search enabled a general collection of articles that explores a breadth of AM research that potentially looks at roughness and is related to powder (since the LPBF process is in focus).

STAGE 2: Once both databases had been searched using both terms, and the initial article lists were compiled, screening was conducted using conditional formatting in a spreadsheet to highlight duplicates and de-duplication was then performed manually.

STAGE 3: Based on a rough scan of the articles and previous experience on AM literature, seven categories were defined to structure the eligibility check (Table 1). Initially, the criterion for an article to be eligible was that it should specifically focus on design guidance through guidelines, methods or tools, with respect to consideration for surface roughness, i.e., category (1). However, to understand the distribution of research related to surface roughness within other fields, categories (2) to (6) were included. Category (7) was added to exclude non-relevant articles that, e.g., focused on other AM processes than LPBF or non-metal materials. Each article was then assigned to a category based on its title and abstract. While the categories were defined at the onset of the eligibility check, each article contributed to the extent of what articles belonged in what category, i.e., the study focus of the article. New categories would have been defined if necessary, but none were added. The eligibility check and categorisation were first performed by one of the authors, which was then cross-checked by the other authors. Articles that the authors categorised differently were then reviewed and re-categorised jointly. After completing the categorisation of the 489 articles it was found that only two articles fulfilled the eligibility criterion of category (1). To better understand how different research fields contribute to the understanding of surface roughness and its implications on product development with LPBF, it was deemed necessary to explore each of the categories (1) to (6). The criterion for an article to be eligible 
was therefore defined so that it should focus on surface roughness in relation to metal LPBF. The remaining 299 articles after the eligibility check were listed for the qualitative synthesis.

STAGE 4 \& 5: Secondary documents were included in the search by using the 'SCOPUS secondary documents' function, and by a visual read-through of the Design Society articles' reference lists. Four articles were added for eligibility assessment from this search. Four weeks after the initial search, follow up searches were conducted by repeating the original searches in both databases, finding six additional articles. These ten articles were all excluded (not relevant) after eligibility assessment.

Table 1. Paper categorisation, their definitions, number of and percentage of articles.

\begin{tabular}{|l|l|c|c|}
\hline ARTICLE CATEGORY & ARTICLE STUDY FOCUS & No. & \% \\
\hline (1) Design & Design processes, methods, guidelines, tools for AM. & 2 & 0 \\
\hline (2) Applications & $\begin{array}{l}\text { Case studies on the application of LPBF for specific } \\
\text { components/parts that are emphasizing surface roughness. }\end{array}$ & 18 & 4 \\
\hline (3) Surface Evaluation & Methods to evaluate and/or measure surface roughness. & 28 & 6 \\
\hline (4) Surface Post-Processing & $\begin{array}{l}\text { Surface treatment methods and their effect on surface } \\
\text { roughness. }\end{array}$ & 61 & 12 \\
\hline (5) Material Properties & Material properties and the impact of surface roughness. & 83 & 17 \\
\hline (6) Build Parameter Study & $\begin{array}{l}\text { How build parameters (e.g., melt theme, layer thickness, } \\
\text { powder size) impact the resulting surface roughness. }\end{array}$ & 107 & 21 \\
\hline (7) Not Relevant & $\begin{array}{l}\text { Other AM processes (e.g., Electron Beam PBF, Direct } \\
\text { Energy Deposition, Binder Jetting), non-metal materials, } \\
\text { exotic metals (e.g., silver), not downloadable, not in English. }\end{array}$ & 200 & 40 \\
\hline
\end{tabular}

STAGE 6: The number of articles and their proportion of the total articles through the eligibility assessment are shown in Table 1. The initial purpose of the review was to focus on articles strictly studying product design for AM and consideration for surface roughness through design processes, methods, guidelines or tools. Out of 299 articles, only two were included in this strict Design category. Most previous research related to surface roughness focus on parameter optimisation and understanding the correlation between different process parameters and the resulting build. I.e., not the actual product design process used to design surfaces. Several of the articles could be categorised in more than one category, depending on the logic chosen. For example, some studies on build parameters contain results that can serve as guidelines for a designer, but if the focus is on process parameter design and optimization, these have been categorised as Build Parameter Study.

\section{SURFACE ROUGHNESS CONSIDERATIONS IN DESIGN FOR AM}

The two articles categorised as focusing on design support discuss a specific tool and a more general design process respectively. Ahn et al. (2007) presents the development of a methodology for optimising the choice of part build direction to reduce the post-process machining area. They create a generic algorithm relating the distribution of surface roughness to the LPBF process parameters, proposing a tool to decide the best part orientation for an AM process. Dordlofva and Törlind (2018) highlight that test artefacts are important for understanding the relationship between LPBF process capabilities and design-related uncertainties for part-specific geometrical features. They propose a design process that utilises test artefacts to resolve such uncertainties and understand how a critical part feature should be designed and built to, for example, minimise surface roughness.

The bulk of literature regarding surface roughness and LPBF generally focuses on understanding how to reduce surface roughness through choices of build angles, optimising process parameters or improving the surface quality through post-processing. Another studied topic is how to measure and characterise the surface. The following synthesis summarises the other relevant categories and how they are related to design considerations regarding surface roughness. Applications (Category 2) are not further discussed in this paper.

\subsection{Build Parameter Studies}

There lies a fundamental relationship between the material properties of the parts produced by an LPBF process and the build parameters of the process (Artzt et al., 2020; Calignano and Minetola, 2019). Build parameter studies were found to be the most common category of articles during the 
search (Table 1). This indicates that researching the relationship between process parameters and AM part properties is an area of active research. Studies commonly review the effects of varying parameters such as powder particle size (Balbaa et al., 2020), laser scanning velocity, scanning strategy, laser power and total energy density (Wang et al., 2016). Other articles look at processspecific relationships, such as the effects of shielding gas flow (Bean et al., 2018).

Table 2. Summary of parameter and surface roughness $(S R)$ relation findings from articles.

\begin{tabular}{|l|l|l|}
\hline FACTOR & SR RELATION FINDING & REFERENCE \\
\hline \multirow{2}{*}{ Laser Power } & As Power $\uparrow$ SR $\uparrow$ & $\begin{array}{l}\text { (Artzt et al., 2020; Khorasani et al., 2020; } \\
\text { Sanaei and Fatemi, 2020; Wang et al., 2016) }\end{array}$ \\
\hline \multirow{2}{*}{ Haser Scan Velocity } & As Velocity $\uparrow$ SR $\downarrow$ & (Artzt et al., 2020; Louw and Pistorius, 2019) \\
\cline { 2 - 3 } & As Velocity $\uparrow$ SR $\uparrow$ & (Baciu et al., 2019; Mohammad et al., 2017) \\
\hline Energy Density & As Hatch $\downarrow$ SR $\downarrow$ & (Louw and Pistorius, 2019) \\
\cline { 2 - 3 } & As Hatch $\uparrow$ SR $\downarrow$ & (Chen et al., 2017; Khorasani et al., 2020) \\
\hline Powder Particle Size & As Energy Density $\uparrow$ SR $\downarrow$ & (Liu et al., 2018; Wang et al., 2016) \\
\cline { 2 - 3 } & As Size $\downarrow$ SR $\uparrow$ & (Balbaa et al., 2021) \\
\hline Laser Focus Shift & As Laser Focus $\downarrow$ SR $\uparrow$ & (Conlon and Azari, 2018) \\
\hline Shielding Gas Flow & Further from gas flow SR $\uparrow$ & (Bean et al., 2018) \\
\hline Re-melting & As number of remelts $\uparrow$ SR $\downarrow$ & (Wang et al., 2016; Yasa et al., 2011) \\
\hline $\begin{array}{l}\text { Surface laser relation } \\
\text { angle }\end{array}$ & $\begin{array}{l}\text { Constant angle produces } \\
\text { homogenous SR }\end{array}$ & (Rott et al., 2020) \\
\hline $\begin{array}{l}\text { Baseplate Part } \\
\text { positioning }\end{array}$ & $\begin{array}{l}\text { From centre to corners, SR } \uparrow \text { for } \\
\text { flat surfaces and SR } \downarrow \text { for } \\
\text { inclined surfaces }\end{array}$ & (Oter et al., 2020) \\
\hline
\end{tabular}

As shown in Table 2, studies have produced contradictory results. Such as Baciu et al. (2019) found that as laser scan velocity increases so may the surface roughness value. However, Artzt et al. (2020) found the converse. Similarly, as particle powder size reduces, enabling the creation of finer features in parts, Balbaa et al. (2021) found that the surface roughness increases, whereas Conlon and Azari (2018) found the opposite. Oter et al. (2020) found through varying part positioning within an EOS machine, that the roughness is dependent on the part geometry and inclination of the walls due to the machine's laser incidence. Increasing the energy density, through varying laser power, scanning velocity, hatch distance or powder layer thickness, leads to an initial reduction in the surface roughness of parts. However, continual increase past an optimal point eventually leads to drastically worse roughness (i.e., as energy density at too low levels is insufficient to melt the powder completely and when at too high levels, too much powder is melted, or evaporation occurs) (Liu et al., 2018; Wang et al., 2016). These findings highlight the need for tuning these parameters to obtain an acceptable surface finish. Unfortunately, many of the parameters influence several properties at the same time. As Artzt et al. (2020) state it: "This reminds of Pandora's box: the roughness cannot be reduced without negatively affecting another important property, the residual stress".

When manufacturing metals using LPBF, the rapid cooling rates, powder spreading methods and directional solidification leads to material microstructural features, which can affect the part material properties such as porosity, non-equilibrium microstructures and anisotropic microstructures (Chen et al., 2019; Gorsse et al., 2017; Malz et al., 2019). Furthermore, defects can be caused by lack of fusion, unmelted or partially melted powder and gas entrapment occurring during the LPBF build process (Eliaz et al., 2020). These issues can impact the surface roughness of an LPBF part which in turn can influence properties (Aliprandi et al., 2019).

\subsection{Material Properties}

Of the 83 articles that were categorised as material properties articles, the metals researched were Titanium alloys (47\%), Stainless steels (30\%), Nickel-based alloys (12\%), Aluminium alloys (7\%) and others $(4 \%)$. 
LPBF properties are often compared against wrought and cast materials, showing that comparable property values can be achieved (Fatemi et al., 2020). However, it has also been shown that surface roughness can severely impact material properties. The fatigue performance of AM parts and its relation to surface roughness has been readily assessed (Eidt et al., 2019; Mower and Long, 2016; Sanaei and Fatemi, 2020), and it was noted as the most common area of research with regards specifically to investigating surface roughness effects. High surface roughness of an as-built AM part correlates with the fatigue performance in a negative way (Dhansay et al., 2014; Molaei and Fatemi, 2018; Shrestha et al., 2019). As-built components with an outer surface with relatively high surface roughness influence the fatigue life of loaded components under, compressive, tensional and bending forces (Balachandramurthi et al., 2018; Bayati et al., 2020; Becker et al., 2020). Similar conclusions are drawn regardless of metal alloy regarding a negative relationship between an increase in surface roughness and lower fatigue performance, particularly in the as-built state (Harada et al., 2020; du Plessis and Beretta, 2020; Sprengel et al., 2019). The lower fatigue strength performance can be attributed to the notch effect and stress concentrations caused by the rough surface defects (Nicoletto et al., 2020; du Plessis and Beretta, 2020).

Surface roughness has also been shown to have a negative effect between the increasing degree of surface roughness and properties such as elongation at break (Ellis et al., 2015), creep (Viespoli et al., 2020) and bending (Frkán et al., 2017). Other commonly researched properties of LPBF materials include compressive strength (Bayati et al., 2020), tribological features (Mondragón-Rodríguez et al., 2020) tensile strength and elongation (Harada et al., 2020).

\subsection{Surface (Post)-Processing}

Due to the inherent nature of the LPBF to produce parts with some level of surface roughness, efficient methods of post-processing are continuing to be developed. Currently to address the surface roughness issues of AM parts, post-processing methods such as abrasive blasting (Sagbas, 2020), shot peening (AlMangour and Yang, 2016) and laser polishing (Zhang et al., 2020) are utilised. The choice of post-processing method can have an impact on the properties of the outer layer of AM parts and part geometry, therefore careful consideration of method choice must be taken (Bouland et al., 2019; Kaynak and Tascioglu, 2020; Sagbas, 2020). However, there are limited available standards to help in the choice of appropriate methods. For example, currently less than $1 \%$ of ISO/ASTM standards are related to surface finishing (Lee et al., 2020). Additionally, for high complexity parts or parts with closed channels, further consideration needs to be made on the choice of finishing method to avoid the post-processing being challenging, costly or unfeasible (Gilbert and Smith, 2020).

Several articles present in situ processing (processes that are performed after contouring and hatching, but before the next powder layer is applied). This processing step includes remelting of the surface as well as laser erosion (subtractive process based on evaporation of material with the energy of the laser beam operated in pulsed mode). Yasa et al. (2011) describe that laser remelting can lower the surface roughness by about $50 \%$ and $75 \%$ for inclination angles of $30^{\circ}$ and $10^{\circ}$ respectively and laser erosion can improve this further. Remelting also has the advantage of enhancing the inner density of the part.

\subsection{Surface Evaluation and Measurement}

Because of the tight correlation between surface roughness and fatigue, it is essential to be able to measure and analyse the surface accurately. Due to the layered approach of LPBF, the surface topology of an AM part can be extremely complex and also different on a vertical wall compared to a top surface (parallel to the powder bed). The surface roughness of AM parts is typically measured with a profilometer to achieve an arithmetical mean height of a line ( $\mathrm{Ra})$. However, due to the complex topology of the surface, it can often not be accurately captured with contact and optical profilometers (Vayssette et al., 2019; Diaz et al., 2019). Also, the surface structure is dependent on the overlap of hatches and hatch strategy. Therefore, the mean height of a surface ( $\mathrm{Sa}$ ) often gives a better estimate of the surface quality because "the variation of average roughness in overlap of hatches can be 5-7 times higher than the centre of the track" (Khorasani et al., 2020).

\section{CONCLUSION}

This paper is an initial synthesis of a literature review describing how and why surface roughness of LPBF produced parts is an area that requires a detailed understanding in the manufacturing of high- 
performance parts. As has been presented in this review, surface roughness negatively impacts properties that dictate the performance of LPBF parts. Research on understanding and improving surface roughness through LPBF process parameter optimisation is a relatively extensively studied area, but still at an early stage. An emerging area is the simulation of surface roughness in relation to process parameter settings, however this is in its infancy. The effect of surface roughness on material properties is an extensively studied field, with much research within AM focusing on material properties in general. The need to understand the implications of AM surface roughness is especially of interest for fatigue sensitive components in industries like aerospace.

Few articles (less than 1\%) focus specifically on design support (such as guidelines, methods, and tools) for engineers. Thus, there is very little support for design engineers (in the design process) who want to consider how surface roughness from an AM process affects the final product. Consideration for surface roughness during design is a significant area for future research and will require a multidisciplinary approach due to the close relationship between the geometrical design of a part, the LPBF process parameters chosen and the resultant material properties. From the review, future research is trending in the direction of utilising the insight from studying surface roughness for predictive fatigue analysis (du Plessis and Beretta, 2020; Sanaei and Fatemi, 2020) and the creation of AM design rules (Piscopo et al., 2019). Artificial neural networks are also utilised to optimise process parameters for a good surface finish (Khorasani et al., 2020). To further understand the consequence of design choice, other studies vary coupon geometries and inclination angles to understand the relation to surface quality of overhanging features (Artzt et al., 2020; Chen et al., 2017). Hence, future research should focus on collating knowledge from the diverse fields of research discussed in this article, using this knowledge to create the guidelines and methods for how to consider surface roughness in design for AM. Additionally, a further refining of the categories used in this review would enable explicit sorting of articles that provide guidance with regard to design, but which are currently within other defined categories (not Design). It would thus narrow article numbers and provide a focus for the next work. Furthermore, this work has been limited through only searching through article titles, abstracts and key words, potentially missing design details within articles of interest which did not include the search terms in theirs. Likewise, not all articles assigned to a category were actually of interest but were considered 'hits' due to mentions of surface roughness in e.g., the abstract.

\section{ACKNOWLEDGMENTS}

The authors acknowledge the financial support from LTU Graduate School of Space Technology and the EU regional growth project RIT (Space for Innovation and Growth). This work is also supported through NRFP (Swedish National Space Research Programme), funded by SNSA (Swedish National Space Agency) and GKN Aerospace Sweden AB.

\section{REFERENCES}

Ahn, D., Kim, H. and Lee, S. (2007), "Fabrication direction optimization to minimize post-machining in layered manufacturing”, International Journal of Machine Tools and Manufacture, Vol. 47 No. 3-4, pp. 593-606. https://doi.org/10.1016/j.ijmachtools.2006.05.004.

Aliprandi, P., Giudice, F., Guglielmino, E. and Sili, A. (2019), "Tensile and Creep Properties Improvement of Ti-6Al-4V Alloy Specimens Produced by Electron Beam Powder Bed Fusion Additive Manufacturing", Metals, Vol. 9 No. 11, p. 1207. https://doi.org/10.3390/met9111207.

AlMangour, B. and Yang, J.-M. (2016), "Improving the surface quality and mechanical properties by shotpeening of 17-4 stainless steel fabricated by additive manufacturing”, Materials \& Design, Elsevier Ltd, Vol. 110, pp. 914-924. https://doi.org/10.1016/j.matdes.2016.08.037.

Artzt, K., Mishurova, T., Bauer, P.-P., Gussone, J., Barriobero-Vila, P., Evsevleev, S., Bruno, G., et al. (2020), "Pandora's Box-Influence of Contour Parameters on Roughness and Subsurface Residual Stresses in Laser Powder Bed Fusion of Ti-6Al-4V”, Materials, Vol. 13 No. 15, p. 3348. https://doi.org/10.3390/ma13153348.

Baciu, A.M., Bejinariu, C., Corăbieru, A., Mihalache, E., Lupu-Poliac, M., Baciu, C. and Baciu, E.R. (2019), "Influence of process parameters for Selective Laser Melting on the roughness of 3D printed surfaces in Co-Cr dental alloy powder”, IOP Conference Series: Materials Science and Engineering, Vol. 572 No. 1, p. 012054. https://doi.org/10.1088/1757-899X/572/1/012054.

Balachandramurthi, A.R., Moverare, J., Dixit, N. and Pederson, R. (2018), "Influence of defects and as-built surface roughness on fatigue properties of additively manufactured Alloy 718”, Materials Science and Engineering A, Vol. 735, pp. 463-474. https://doi.org/10.1016/j.msea.2018.08.072. 
Balbaa, M.A., Ghasemi, A., Fereiduni, E., Elbestawi, M.A., Jadhav, S.D. and Kruth, J.-P. (2021), "Role of powder particle size on laser powder bed fusion processability of AlSi10mg alloy", Additive Manufacturing, Vol. 37, p. 101630. https://doi.org/10.1016/j.addma.2020.101630.

Bayati, P., Safaei, K., Nematollahi, M., Jahadakbar, A., Yadollahi, A., Mahtabi, M. and Elahinia, M. (2020), "Toward understanding the effect of remelting on the additively manufactured NiTi", International Journal of Advanced Manufacturing Technology. https://doi.org/10.1007/s00170-020-06378-4.

Bean, G.E., Witkin, D.B., McLouth, T.D., Patel, D.N. and Zaldivar, R.J. (2018), "Effect of laser focus shift on surface quality and density of Inconel 718 parts produced via selective laser melting", Additive Manufacturing, Vol. 22, pp. 207-215. https://doi.org/10.1016/j.addma.2018.04.024.

Becker, T.H., Dhansay, N.M., Haar, G.M. Ter and Vanmeensel, K. (2020), "Near-threshold fatigue crack growth rates of laser powder bed fusion produced Ti-Aal-4V”, Acta Materialia, Elsevier Ltd, Vol. 197, pp. 269-282. https://doi.org/10.1016/j.actamat.2020.07.049.

Bouland, C., Urlea, V., Beaubier, K., Samoilenko, M. and Brailovski, V. (2019), “Abrasive flow machining of laser powder bed-fused parts: Numerical modeling and experimental validation”, Journal of Materials Processing Technology, Vol. 273. https://doi.org/10.1016/j.jmatprotec.2019.116262.

Calignano and Minetola. (2019), "Influence of Process Parameters on the Porosity, Accuracy, Roughness, and Support Structures of Hastelloy X Produced by Laser Powder Bed Fusion”, Materials, Vol. 12 No. 19, p. 3178. https://doi.org/10.3390/ma12193178.

Chen, H., Gu, D., Xiong, J. and Xia, M. (2017), "Improving additive manufacturing processability of hard-toprocess overhanging structure by selective laser melting", Journal of Materials Processing Technology, Vol. 250, pp. 99-108. https://doi.org/10.1016/j.jmatprotec.2017.06.044.

Chen, R., Imani, F., Reutzel, E. and Yang, H. (2019), "From Design Complexity to Build Quality in Additive Manufacturing-A Sensor-Based Perspective”, IEEE Sensors Letters, Vol. 3 No. 1. https://doi.org/10.1109/LSENS.2018.2880747.

Conlon, M.J. and Azari, K. (2018), "Impact of powder size, size distribution and morphology on additive manufacturing", Advances in Powder Metallurgy and Particulate Materials - 2018: Proceedings of the 2018 International Conference on Powder Metallurgy and Particulate Material, POWDERMET 2018, Vol. 2018 June, pp. 745-754.

Dhansay, N.M., Tait, R. and Becker, T. (2014), Fatigue and Fracture Toughness of Ti-6Al-4V Titanium Alloy Manufactured by Selective Laser Melting, Advanced Materials Research, Vol. 1019. https://doi.org/10.4028/www.scientific.net/AMR.1019.248.

Diaz, A. (2019), "Surface texture characterization and optimization of metal additive manufacturing-produced components for aerospace applications", Additive Manufacturing for the Aerospace Industry, Elsevier, pp. 341-374. https://doi.org/10.1016/B978-0-12-814062-8.00018-2.

Diegel, O., Nordin, A. and Motte, D. (2019), A Practical Guide to Design for Additive Manufacturing, Springer Singapore, Singapore, available at: http://link.springer.com/10.1007/978-981-13-8281-9 (accessed 11 December 2020). https://doi.org/10.1007/978-981-13-8281-9.

Dordlofva, C., Brodin, S. and Andersson, C. (2019), "Using demonstrator hardware to develop a future qualification logic for additive manufacturing parts", Proceedings of the International Astronautical Congress, IAC.

Dordlofva, C. and Törlind, P. (2018), "Design for qualification: A process for developing additive manufacturing components for critical systems", Proceedings of NordDesign: Design in the Era of Digitalization, NordDesign 2018.

Dordlofva, C. and Törlind, P. (2020), "Evaluating design uncertainties in additive manufacturing using design artefacts: examples from space industry”, Design Science, Vol. 6, p. e12. https://doi.org/10.1017/dsj.2020.11.

Eidt, W., Tatman, E.P., McCarther, J., Kastner, J., Gunther, S. and Gockel, J. (2019), "Surface roughness characterization in laser powder bed fusion additive manufacturing", Solid Freeform Fabrication 2019: Proceedings of the 30th Annual International Solid Freeform Fabrication Symposium - An Additive Manufacturing Conference, SFF 2019, pp. 2165-2176.

Eliaz, N., Foucks, N., Geva, D., Oren, S., Shriki, N., Vaknin, D., Fishman, D., et al. (2020), “Comparative quality control of titanium alloy Ti-6Al-4V, 17-4 PH stainless steel, and aluminum alloy 4047 either manufactured or repaired by laser engineered net shaping (LENS)", Materials, Vol. 13 No. 18. https://doi.org/10.3390/ma13184171.

Ellis, A., Brown, R. and Hopkinson, N. (2015), "The effect of build orientation and surface modification on mechanical properties of high speed sintered parts", Surface Topography: Metrology and Properties, Vol. 3 No. 3. https://doi.org/10.1088/2051-672X/3/3/034005.

Ewald, A. and Schlattmann, J. (2018), "Design guidelines for laser metal deposition of lightweight structures", Journal of Laser Applications, Vol. 30 No. 3. https://doi.org/10.2351/1.5040612.

Fatemi, A., Molaei, R. and Phan, N. (2020), "Multiaxial fatigue of additive manufactured metals: Performance, analysis, and applications", International Journal of Fatigue, Vol. 134, p. 105479. https://doi.org/10.1016/j.ijfatigue.2020.105479. 
Frkán, M., Konecná, R. and Nicoletto, G. (2017), "Surface quality and fabrication directionality effects on the fatigue behavior of DMLS Ti6Al4V”, METAL 2017 - 26th International Conference on Metallurgy and Materials, Conference Proceedings, Vol. 2017-Janua, pp. 1567-1572.

Gilbert, D. and Smith, B. (2020), "A flexible finishing solution to accelerate the uptake of AM components into high value manufacturing industries", Euro PM 2018 Congress and Exhibition.

Gorsse, S., Hutchinson, C., Gouné, M. and Banerjee, R. (2017), "Additive manufacturing of metals: a brief review of the characteristic microstructures and properties of steels, Ti-6Al-4V and high-entropy alloys", Science and Technology of Advanced Materials, Vol. 18 No. 1, pp. 584-610. https://doi.org/10.1080/14686996.2017.1361305.

Harada, Y., Ishida, Y., Miura, D., Watanabe, S., Aoki, H., Miyasaka, T. and Shinya, A. (2020), "Mechanical properties of selective laser sintering pure titanium and ti-6al-4v, and its anisotropy", Materials, Vol. 13 No. 22, pp. 1-18. https://doi.org/10.3390/ma13225081.

ISO/ASTM 52910. (2018), “Additive manufacturing — Design — Requirements, guidelines and recommendations", ISO/ASTM.

ISO/ASTM 52911-1-19. (2019), Additive Manufacturing — Design — Part 1: Laser-Based Powder Bed Fusion of Metals, ASTM International.

Kaynak, Y. and Tascioglu, E. (2020), "Post-processing effects on the surface characteristics of Inconel 718 alloy fabricated by selective laser melting additive manufacturing", Progress in Additive Manufacturing, Vol. 5 No. 2, pp. 221-234. https://doi.org/10.1007/s40964-019-00099-1.

Khorasani, A.M., Gibson, I., Ghasemi, A. and Ghaderi, A. (2020), "Modelling of laser powder bed fusion process and analysing the effective parameters on surface characteristics of Ti-6Al-4V", International Journal of Mechanical Sciences, Vol. 168, p. 105299. https://doi.org/10.1016/j.ijmecsci.2019.105299.

Kokkonen, P., Salonen, L., Virta, J., Hemming, B., Laukkanen, P. and Savolainen, M. (2016), "Design guide for additive manufacturing of metal components by SLM process", Digital Open Access Repository of VTT, VTT Technical Research Centre of Finland, p. 131.

Lee, J.-Y., Nagalingam, A.P. and Yeo, S.H. (2020), "A review on the state-of-the-art of surface finishing processes and related ISO/ASTM standards for metal additive manufactured components", Virtual and Physical Prototyping, pp. 1-29. https://doi.org/10.1080/17452759.2020.1830346.

Liu, Z., Wang, X., Kim, H., Zhou, Y., Cong, W. and Zhang, H. (2018), "Investigations of Energy Density Effects on Forming Accuracy and Mechanical Properties of Inconel 718 Fabricated by LENS Process", Procedia Manufacturing, Vol. 26, pp. 731-739. https://doi.org/10.1016/j.promfg.2018.07.083.

Louw, D.F. and Pistorius, P.G.H. (2019), "The effect of scan speed and hatch distance on prior-beta grain size in laser powder bed fused Ti-6Al-4V", International Journal of Advanced Manufacturing Technology, Vol. 103 No. 5-8, pp. 2277-2286. https://doi.org/10.1007/s00170-019-03719-w.

Malz, S., Nosir, S., Trudel, E., Elsayed, M.S.A., Kok, L. and Provost, E. (2019), "Effect of ultrasonic impact treatment on the stress-controlled fatigue performance of additively manufactured ti-6al-4v alloy", AIAA Scitech 2019 Forum. https://doi.org/10.2514/6.2019-0414.

Mohammad, A., Al-Ahmari, A.M., AlFaify, A. and Mohammed, M.K. (2017), "Effect of melt parameters on density and surface roughness in electron beam melting of gamma titanium aluminide alloy", Rapid Prototyping Journal, Vol. 23 No. 3, pp. 474-485. https://doi.org/10.1108/RPJ-12-2014-0187.

Moher, D., Liberati, A., Tetzlaff, J., Altman, D.G. and Group, T.P. (2009), "Preferred Reporting Items for Systematic Reviews and Meta-Analyses: The PRISMA Statement", Vol. 6 No. 7. https://doi.org/10.1371/journal.pmed.1000097.

Molaei, R. and Fatemi, A. (2018), "Fatigue Design with Additive Manufactured Metals: Issues to Consider and Perspective for Future Research", Procedia Engineering, Vol. 213, pp. 5-16. https://doi.org/10.1016/j.proeng.2018.02.002.

Mondragón-Rodríguez, G.C., Torres-Padilla, N., Camacho, N., Espinosa-Arbeláez, D.G., de León-Nope, G. V., González-Carmona, J.M. and Alvarado-Orozco, J.M. (2020), "Surface modification and tribological behavior of plasma nitrided Inconel 718 manufactured via direct melting laser sintering method", Surface and Coatings Technology, Vol. 387. https://doi.org/10.1016/j.surfcoat.2020.125526.

Mower, T.M. and Long, M.J. (2016), "Mechanical behavior of additive manufactured, powder-bed laser-fused materials", Materials Science and Engineering A, Vol. 651, pp. 198-213. https://doi.org/10.1016/j.msea.2015.10.068.

Nicoletto, G., Konečna, R., Frkan, M. and Riva, E. (2020), "Influence of layer-wise fabrication and surface orientation on the notch fatigue behavior of as-built additively manufactured Ti6Al4V", International Journal of Fatigue, Vol. 134 No. October 2019. https://doi.org/10.1016/j.ijfatigue.2020.105483.

Oter, Z.C., Coskun, M. and Koc, E. (2020), "Effect of building platform position on the surface quality, dimensional accuracy, and geometrical precision of direct metal laser sintering (DMLS) parts", Euro PM 2018 Congress and Exhibition.

Piscopo, G., Salmi, A. and Atzeni, E. (2019), “On the quality of unsupported overhangs produced by laser powder bed fusion", International Journal of Manufacturing Research, Vol. 14 No. 2, pp. 198-216. https://doi.org/10.1504/IJMR.2019.100012. 
du Plessis, A. and Beretta, S. (2020), "Killer notches: The effect of as-built surface roughness on fatigue failure in AlSi10Mg produced by laser powder bed fusion", Additive Manufacturing, Elsevier, Vol. 35 No. June, p. 101424. https://doi.org/10.1016/j.addma.2020.101424.

Rott, S., Ladewig, A., Friedberger, K., Casper, J., Full, M. and Schleifenbaum, J.H. (2020), "Surface roughness in laser powder bed fusion - Interdependency of surface orientation and laser incidence", Additive Manufacturing, Elsevier B.V., Vol. 36. https://doi.org/10.1016/j.addma.2020.101437.

Sagbas, B. (2020), "Post-Processing Effects on Surface Properties of Direct Metal Laser Sintered AlSi10Mg Parts", Metals and Materials International, Vol. 26 No. 1, pp. 143-153. https://doi.org/10.1007/s12540-01900375-3.

Saltzman, D., Bichnevicius, M., Lynch, S., Simpson, T.W., Reutzel, E.W., Dickman, C. and Martukanitz, R. (2018), "Design and evaluation of an additively manufactured aircraft heat exchanger", Applied Thermal Engineering, Vol. 138, pp. 254-263. https://doi.org/10.1016/j.applthermaleng.2018.04.032.

Sanaei, N. and Fatemi, A. (2020), "Analysis of the effect of surface roughness on fatigue performance of powder bed fusion additive manufactured metals", Theoretical and Applied Fracture Mechanics, Elsevier, Vol. 108 No. May, p. 102638. https://doi.org/10.1016/j.tafmec.2020.102638.

Schnabel, T., Oettel, M. and Mueller, B. (2017), Design for Additive Manufacturing Guidelines and Case Studies for Metal Applications Prepared for Industry Canada-Manufacturing \& Life Sciences Branch, Dresden.

Shrestha, R., Simsiriwong, J. and Shamsaei, N. (2019), "Fatigue behavior of additive manufactured 316L stainless steel parts: Effects of layer orientation and surface roughness", Additive Manufacturing, Vol. 28, pp. 23-38. https://doi.org/10.1016/j.addma.2019.04.011.

Sprengel, M., Baca, A., Gumpinger, J., Connolley, T., Brandao, A., Rohr, T. and Ghidini, T. (2019), Fatigue Properties of Powder Bed Fused Inconel 718 in As-Built Surface Condition, Structural Integrity, Vol. 7. https://doi.org/10.1007/978-3-030-13980-3_12.

Vayssette, B., Saintier, N., Brugger, C., El May, M. and Pessard, E. (2019), "Numerical modelling of surface roughness effect on the fatigue behavior of Ti-6Al-4V obtained by additive manufacturing", International Journal of Fatigue, Vol. 123, pp. 180-195. https://doi.org/10.1016/j.ijfatigue.2019.02.014.

VDI 3405 Part 3. (2015), “Additive manufacturing processes, rapid manufacturing Design rules for part production using laser sintering and laser beam melting".

Viespoli, L.M., Bressan, S., Itoh, T., Hiyoshi, N., Prashanth, K.G. and Berto, F. (2020), "Creep and high temperature fatigue performance of as build selective laser melted Ti-based 6Al-4V titanium alloy", Engineering Failure Analysis, Elsevier, Vol. 111 No. October 2019, p. 104477. https://doi.org/10.1016/j.engfailanal.2020.104477.

Wang, D., Liu, Y., Yang, Y. and Xiao, D. (2016), "Theoretical and experimental study on surface roughness of 316L stainless steel metal parts obtained through selective laser melting", Rapid Prototyping Journal, Vol. 22 No. 4, pp. 706-716. https://doi.org/10.1108/RPJ-06-2015-0078.

Wang, D., Mai, S., Xiao, D. and Yang, Y. (2016), "Surface quality of the curved overhanging structure manufactured from 316-L stainless steel by SLM", The International Journal of Advanced Manufacturing Technology, Vol. 86 No. 1-4, pp. 781-792. https://doi.org/10.1007/s00170-015-8216-6.

Yasa, E., Deckers, J. and Kruth, J.-P. (2011), "The investigation of the influence of laser re-melting on density, surface quality and microstructure of selective laser melting parts", Rapid Prototyping Journal, Vol. 17 No. 5, pp. 312-327. https://doi.org/10.1108/13552541111156450.

Zhang, D., Yu, J., Li, H., Zhou, X., Song, C., Zhang, C., Shen, S., et al. (2020), "Investigation of laser polishing of four selective laser melting alloy samples", Applied Sciences (Switzerland), Vol. 10 No. 3.

https://doi.org/10.3390/app10030760. 